\title{
Benign metastasizing leiomyoma and 18-FDG-PET/CT: A case report and literature review
}

\author{
YUSUKE SAWAI, TOSHIKI SHIMIZU, YUTA YAMANAKA, MAIKO NIKI and SHOSAKU NOMURA \\ First Department of Internal Medicine, Kansai Medical University, Moriguchi, Osaka 570-8507, Japan
}

Received August 23, 2016; Accepted March 10, 2017

DOI: $10.3892 / \mathrm{ol} .2017 .6609$

\begin{abstract}
Pulmonary benign metastasizing leiomyoma (PBML) is a rare disease entity that usually occurs in females of reproductive age with a previous history of uterine myoma. It is typically characterized by multiple pulmonary tumors consisting of benign leiomyoma cells. In the present study, two cases of PBML are discussed. The patient in each case underwent 2-deoxy-2-(fluorine-18)-fluoro-D-glu cose positron emission tomography/computed tomography (18-FDG-PET/CT) scans. One patient demonstrated a lack of 18-FDG uptake and a quiescent clinical course. However, the second patient exhibited a markedly high uptake of 18-FDG and aggressive cell proliferation. The two tumors revealed significant differences in metabolic behavior and in clinical course; however, they were similar with regard to cellular appearance. A review of previous studies concerning the findings of 18-FDG-PET/CT in published cases of PBML was also conducted and is presented here.
\end{abstract}

\section{Introduction}

Pulmonary benign metastasizing leiomyoma (PBML) is a rare disease entity that usually occurs in females of reproductive age with a prior history of uterine myoma. PBML was first described by Steiner in 1939 (1). PBML is typically characterized by multiple pulmonary tumors containing benign leiomyoma cells (2). Patients are usually asymptomatic and the tumors grow gradually (3). In the present study, two cases of PBML are presented, each of which include the results of 2-deoxy-2-(fluorine-18)-fluoro-D-glucose positron emission tomography/computed tomography (18-FDG-PET/CT) scans. The first patient demonstrated an absence of 18-FDG uptake and a quiescent clinical course. However, the second patient

Correspondence to: Dr Toshiki Shimizu, First Department of Internal Medicine, Kansai Medical University, 10-15 Fumizono-cho, Moriguchi, Osaka 570-8507, Japan

E-mail: shimizto@takii.kmu.ac.jp

Key words: benign metastasizing leiomyoma, 2-deoxy-2-(fluori ne-18)-fluoro-D-glucose positron emission tomography/computed tomography exhibited a markedly high uptake of 18-FDG and the aggressive proliferation of tumor cells was detected. The two tumors revealed significant differences in metabolic behavior and clinical course, yet were alike in regard to cellular appearance. A literature review on the findings of 18-FDG-PET/CT scans in previous published cases of PBML was also conducted and is discussed here.

\section{Case}

Case 1. A 38-year-old female was diagnosed with papillary adenocarcinoma of the thyroid gland following a fine-needle aspiration biopsy in Kansai Medical University Takii Hospital in July 2009. However, a CT scan of the chest revealed the presence of multiple nodules of varying sizes in each of the lungs (Fig. 1A). Consequently, an 18-FDG-PET/CT scan was performed. A lesion with high 18-FDG uptake [maximum standard uptake value $\left(\mathrm{SUV}_{\text {max }}\right),>4.9$ ] was observed in the left lobe of the thyroid gland (Fig. 1B and C). However, the results revealed that none of the pulmonary nodules demonstrated 18-FDG uptake (SUV $\mathrm{Smax}_{\text {max }},<1.6$; Fig. $1 \mathrm{C}$ and D). To elucidate whether the pulmonary nodules were metastatic, a CT-guided needle biopsy of the lungs was performed.

Histological examination was performed as part of routine clinical practice. Briefly, the $7-\mu \mathrm{m}$ thick sections obtained from formalin-fixed and paraffin-embedded tissues were used for further examination. Resected tissue was fixed in $10 \%$ formalin neutral buffer solution (Muto Pure Chemicals Co., Ltd., Tokyo, Japan) at room temperature overnight. Hematoxylin and eosin (H\&E) staining was used according to standard clinical histological examination. Light microscopy (BM43/DP27, original magnification, x400; Olympus Corporation, Tokyo, Japan) was used for observation. H\&E staining was performed with Tissue-Tek DRS Slide Stainer (Sakura Fine Tek Europe B.V., Flemingweg, Netherlands) according to manufacturer's protocol. Immunohistochemical staining for aSMA and Ki-67 was performed with Histofine Histostainer 36A (Nichirei Biosciences Inc., Tokyo, Japan) using primary antibodies against $\alpha$ SMA and Ki-67 according to manufacturer's protocol.

The $4 \mu \mathrm{m}$ thick sections obtained from formalin-fixed and paraffin-embedded tissues were deparaffinized in xylene and rehydrated in a graded series of alcohol to water. Antigen retrieval was performed using $10 \mathrm{mM}$ citrate buffer ( $\mathrm{pH}$ 6.0) at $121^{\circ} \mathrm{C}$ for $15 \mathrm{~min}$. Sections were washed in TBS. Antigen 
retrieval was not performed when examining the expression of $\alpha$ SMA. Sections were blocked with $3 \% \mathrm{H}_{2} \mathrm{O}_{2}$ at room temperature for $10 \mathrm{~min}$ and then incubated for $1 \mathrm{~h}$ at room temperature with the antibodies against $\alpha$ SMA (catalog no. 712021; clone no. 1A4; pre-diluted working solution for Histostainer) or Ki-67 (catalog no. 718017; clone no. SP6; pre-diluted working solution for Histostainer) (both from Nichirei Biosciences Inc., Tokyo, Japan).

The sections were subsequently incubated with the Histofine Simple Stain MAX PO (Nichirei Biosciences Inc.) for $30 \mathrm{~min}$ at room temperature according to the manufacturer's protocol. Staining was visualized by adding 3,3'diaminobenzidine (K5007; Dako; Agilent Technologies, Inc., Santa Clara, CA, USA) for $10 \mathrm{~min}$ at room temperature. Sections were counterstained with haematoxylin for $1 \mathrm{~min}$ and then dehydrated with a series of alcohols and xylene.

The lung biopsy tissue specimen revealed a disordered arrangement of spindle-shaped tumor cells (Fig. 2A), and immunohistochemical examination indicated that the cells stained positive for $\alpha$-smooth muscle actin ( $\alpha$-SMA). The $\mathrm{Ki}-67$ ratio was $<1 \%$ (Fig. $2 \mathrm{~B}$ and $\mathrm{C}$ ). These findings were consistent with the phenotypic characteristics of benign leiomyoma (1). At the age of 37, the patient had experienced extensive genital bleeding due to a uterine myoma, and an emergency total hysterectomy with a right oophorectomy was performed. Histological examination of the preexisting uterine myoma tissue specimens, which were obtained during a previous surgical resection (Japan Community Health Care Organization Hoshigaoka Medical Center, Osaka, Japan), was performed as aforementioned. The results of the histological examination revealed the presence of intravascular leiomyomatosis, which is associated with the pathogenesis of PBML (4). Thus, a definitive diagnosis of PBML was established.

As the pulmonary lesions were not attributable to metastases of thyroid cancer, the patient underwent a subtotal thyroidectomy with a curative intention. The tumor-node-metastasis classification pathological stage of the tumor was identified to be pT1aN1aM0 (5). With regard to PBML, observation without the use of aggressive therapy is recommended when the tumor is clinically quiescent (3).

Case 2. A 62-year-old post-menopausal female was referred to Kansai Medical University Takii Hospital for an investigation due to the presence of numerous pulmonary nodules detected in a routine chest radiography in August 2013. The patient had experienced bilateral upper back pain for two weeks prior to the first appointment at this hospital. The patient had no history of uterine myoma. A chest CT revealed the presence of a tumor in the right upper lung that was $60 \mathrm{~mm}$ in diameter and numerous nodular lesions of varying sizes in each of the lungs, in addition to a soft tissue mass that was $70 \mathrm{~mm}$ in diameter in the left second rib (Fig. 3A). The parameters assessed included complete blood count and standard clinical laboratory examinations, and the expression levels of specific tumor markers were within normal limits, including carcinoembryonic antigen, serum cytokeratin-19 fragments and Pro-gastrin-releasing pepetide. Contrast-enhanced magnetic resonance imaging of the head revealed a tumor in the left parietal lobe that was $20 \mathrm{~mm}$ in diameter, with an edema. As the patient was
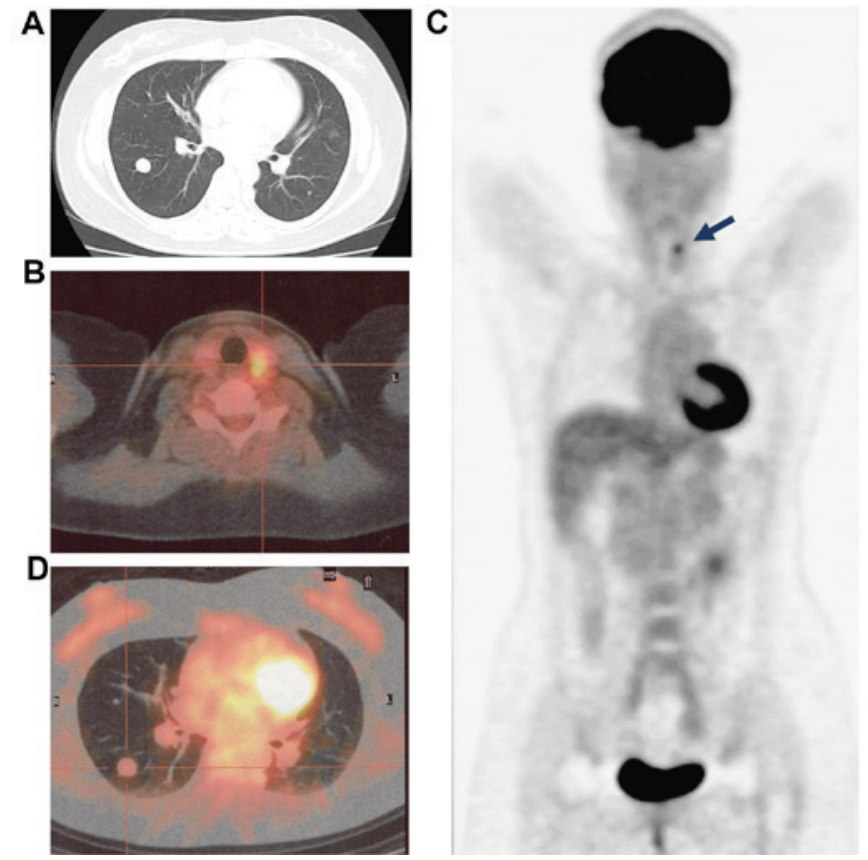

Figure 1. Radiological findings for case 1. (A) CT scan of the pulmonary nodule. (B) A lesion exhibiting high 18-FDG uptake $\left(\mathrm{SUV}_{\max },>4.9\right)$ was detected in the tumor of the left lobe of the thyroid gland (arrow). (C) The fusion image of 18-FDG-PET/CT in the coronal plane. Only one lesion in the thyroid gland exhibited a positive accumulation of 18-FDG (arrow). (D) The fusion image of 18 -FDG-PET/CT in the horizontal plane. The pulmonary nodule demonstrated no significant 18-FDG uptake $\left(\mathrm{SUV}_{\max },<1.6\right)$. CT, computed tomography; 18-FDG-PET/CT, 2-deoxy-2-(fluorine-18)-fluoroD-glucose positron emission tomography/CT; $\mathrm{SUV}_{\max }$, maximum standard uptake value.

suspected to have a lung cancer with pulmonary, bone and brain metastases, an 18-FDG-PET/CT scan was performed. The results indicated abnormally high $18-F D G$ uptake in the right upper lung tumor, the left third rib tumor, atlas vertebra, fourth thoracic vertebra, bilateral ilia and multiple bilateral pulmonary nodules in the lungs (Fig. 3B-D; $\mathrm{SUV}_{\max }, 20.1$ ). Subsequently, a CT-guided needle biopsy of the right upper lung tumor was performed. Histological examination of the lung biopsy tissue specimen revealed a disordered arrangement of spindle-shaped tumor cells with mild atypia (Fig. 2D). Immunohistochemical examination revealed that the cells stained positive for $\alpha$-SMA (Fig. 2E). By contrast, CD34, $\mathrm{S}-100$, estrogen receptor (ER) and progesterone receptor (PgR) expression was not detected in these cells. The Ki-67 ratio was $<1 \%$ (Fig. $2 \mathrm{~F}$ ). These findings are consistent with the phenotypic characteristics of benign leiomyoma. In order to confirm the pathological diagnosis, an additional CT-guided needle biopsy of the tumor of the left rib was performed. The results of the second biopsy tissue specimen from the tumor of the left rib corroborated the findings from the first biopsy specimen obtained from the tumor in the right lung. Consequently, a definitive diagnosis of PBML was established. The patient received whole brain irradiation followed by palliative irradiation for the pulmonary nodules in the right upper lung and left second rib. However, no treatment response was observed and the tumors were identified to be growing (Fig. 4). After three months, the patient was re-admitted to hospital due to a consciousness 

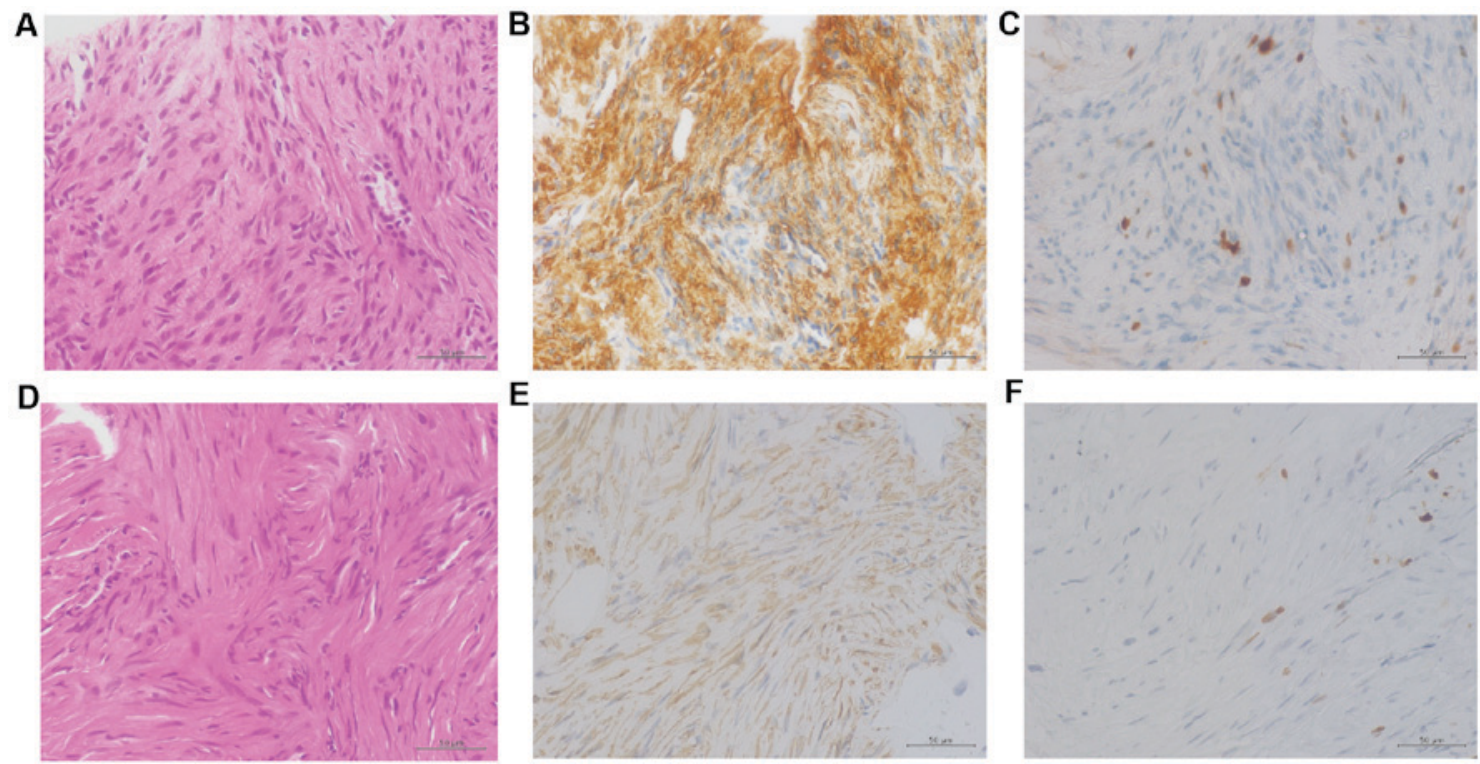

Figure 2. Histological findings of the biopsy tissue specimen. (A-C) The histological findings of the biopsy specimen from case 1. (D-F) The histological findings of the biopsy specimen from case 2. (A and D) Results of H\&E staining. The tissue samples exhibited a similar appearance consisting of interlaced bundles of spindle shaped tumor cells. (B and E) Immunohistochemical staining for $\alpha$-SMA. The tumor cells each stained positive for $\alpha$-SMA. ( $\mathrm{C}$ and F) Immunohistochemical staining for Ki-67 antigen. Staining for Ki-67 revealed positive expression in $<1 \%$ of the two tumors. Original magnification, x400. H\&E, hematoxylin and eosin. $\alpha$-SMA $\alpha$-smooth muscle actin.
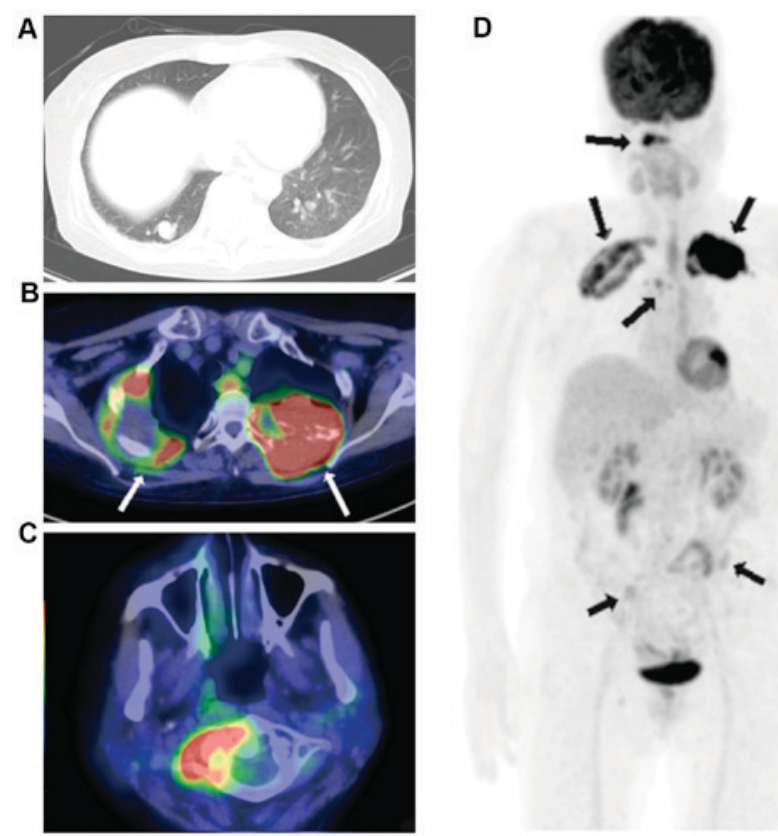

Figure 3. Radiological findings for case 2. (A) The image of CT for pulmonary nodule. (B) The fusion image of 18 -FDG-PET/CT in horizontal plane. The left pulmonary nodule exhibited a notably high 18-FDG uptake $\left(\mathrm{SUV}_{\max },>20.1\right)$. The right pleural thickening also demonstrated marked 18-FDG uptake $\left(\mathrm{SUV}_{\max },>10.1\right)$. (C) A lesion exhibiting high 18-FDG uptake $\left(\mathrm{SUV}_{\max },>12.1\right)$ was detected in the right side of the atlas vertebra. (D) The fusion image of 18-FDG-PET/CT in the coronal plane. Numerous lesions had a positive accumulation of 18-FDG (arrows). CT, computed tomography; 18-FDG-PET/CT, 2-deoxy-2-(fluorine-18)-fluoro-D-glucose positron emission tomography/CT; $\mathrm{SUV}_{\max }$, maximum standard uptake value.

disorder. Corticosteroids and glycerin were administered, and the neurological symptoms were temporarily improved. However, the patient succumbed to septicemia with Clostridium perfringens.
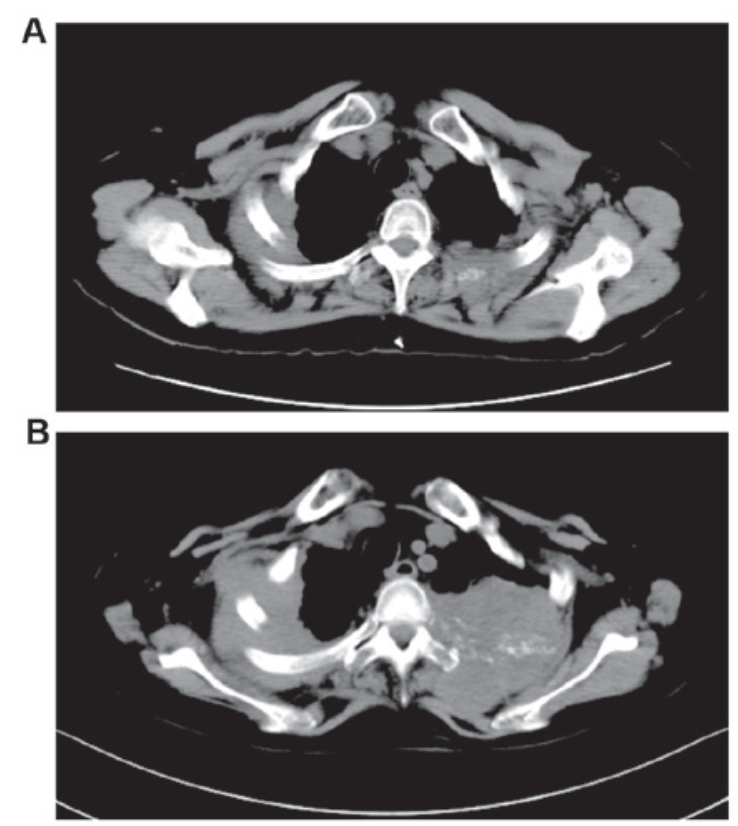

Figure 4. Time-dependent change in the radiological findings for Case 2. (A) The CT scan image of pleural thickening at the initial appointment. (B) The CT scan of pleural thickening at the time of readmission. CT, computed tomography.

\section{Discussion}

To date, the metabolic behavior of PBML in 18-FDG-PET/CT has attracted a high degree of interest. A number of previous reports have demonstrated that there is a lack of 18-FDG uptake in PBML. However, to the best of our knowledge, there has not yet been a systematic review with respect to the 18-FDG-PET/CT findings for PBML. Therefore, a literature review of prior case reports concerning patients with PBML 
Table I. Characteristics of patients with PBML with 18-FDG-PET/CT findings.

\begin{tabular}{|c|c|c|c|c|c|c|c|}
\hline Author, year & Age & Status & FDG uptake $\left(\mathrm{SUV}_{\max }\right)$ & Ki-67 index & ER & $\mathrm{PgR}$ & (Refs.) \\
\hline \multicolumn{7}{|l|}{ Chan et al, 2005} & (6) \\
\hline Case 1 & 49 & Pre & No uptake (ca.1.4) & $\mathrm{NE}$ & + & + & \\
\hline Case 2 & 45 & HRT & No uptake (ca.2.0) & NE & $\mathrm{NE}$ & $\mathrm{NE}$ & \\
\hline Moon et al, 2009 & 52 & Post & No uptake (NE) & $\mathrm{NE}$ & + & + & (7) \\
\hline di Scioscio et al, 2009 & 64 & HRT & No uptake (NE) & $<1 \%$ & + & + & (8) \\
\hline Lee, 2007 & 51 & $\mathrm{NE}$ & No uptake (NE) & $\mathrm{NE}$ & $\mathrm{NE}$ & $\mathrm{NE}$ & (9) \\
\hline Londero et al, 2008 & 52 & HRT & Low uptake (NE) & NE & + & + & $(10)$ \\
\hline Kasai et al, 2009 & 53 & HRT & No uptake (NE) & $\mathrm{NE}$ & - & + & (11) \\
\hline \multicolumn{7}{|l|}{ Lin et al, 2010} & (12) \\
\hline Case 1 & 38 & $\mathrm{NE}$ & Low uptake (0.2-2.2) & NE & $\mathrm{NE}$ & $\mathrm{NE}$ & \\
\hline Case 2 & 37 & HRT & Non avid (0.7-2.9) & $\mathrm{NE}$ & $\mathrm{NE}$ & $\mathrm{NE}$ & \\
\hline Clément-Duchêne et al, 2010 & 55 & HRT & No uptake (NE) & NE & $\mathrm{NE}$ & $\mathrm{NE}$ & (13) \\
\hline Lin and Bradshaw, 2010 & 44 & Pre & No uptake (NE) & NE & + & + & (14) \\
\hline Caminati et al, 2011 & 69 & $\mathrm{NE}$ & No uptake (NE) & NE & + & + & (15) \\
\hline Ogawa et al, 2011 & 65 & $\mathrm{NE}$ & Low uptake (ca.3.8) & $\mathrm{NE}$ & $\mathrm{NE}$ & $\mathrm{NE}$ & (16) \\
\hline Yoon et al, 2011 & 34 & Pre & Faint uptake (NE) & NE & $\mathrm{NE}$ & $\mathrm{NE}$ & (17) \\
\hline Ni et al, 2012 & 46 & $\mathrm{NE}$ & Non avid (ca.3.1) & $\mathrm{NE}$ & $\mathrm{NE}$ & $\mathrm{NE}$ & (18) \\
\hline Nakajo et al, 2012 & 50 & HRT & No uptake (ca.1.5) & $<1 \%$ & + & + & (19) \\
\hline Fu et al, 2012 & 46 & HRT & No uptake (NE) & $<5 \%$ & $\mathrm{NE}$ & + & (20) \\
\hline Alraiyes et al, 2013 & 40 & HRT & No uptake (NE) & NE & + & + & (21) \\
\hline Okabe et al, 2013 & 47 & Pre & No uptake (NE) & NE & + & $\mathrm{NE}$ & (22) \\
\hline \multicolumn{7}{|l|}{ Tsunooka et al, 2013} & (23) \\
\hline Case 1 & 51 & $\mathrm{NE}$ & No uptake (NE) & $<1 \%$ & + & + & \\
\hline Case 2 & 58 & HRT & No uptake (NE) & $<1 \%$ & + & + & \\
\hline Mogi et al, 2013 & 35 & $\mathrm{NE}$ & No uptake (NE) & NE & + & + & (24) \\
\hline \multicolumn{7}{|l|}{ Chen et al, 2013} & (25) \\
\hline Case 1 & 47 & $\mathrm{NE}$ & No uptake (NE) & NE & + & + & \\
\hline Case 2 & 47 & HRT & Moderately (NE) & $<3 \%$ & + & + & \\
\hline Case 3 & 53 & $\mathrm{NE}$ & Moderately (NE) & $<5 \%$ & + & + & \\
\hline Ağaçkiran et al, 2013 & 44 & HRT & Increased (1.92-4.60) & $<3 \%$ & + & + & (26) \\
\hline Loukeri et al, 2014 & 47 & Pre & Low uptake (ca.2.2) & $<3 \%$ & + & $\mathrm{NE}$ & (27) \\
\hline Jeon et al, 2013 & 57 & HRT & Low uptake (NE) & $\mathrm{NE}$ & + & + & (28) \\
\hline Okita et al, 2013 & 44 & HRT & No uptake (NE) & $\mathrm{NE}$ & $\mathrm{NE}$ & $\mathrm{NE}$ & (29) \\
\hline Jin et al, 2013 & 43 & HRT & Minimal (0.9-1.8) & $<1 \%$ & + & + & (30) \\
\hline Taftaf et al, 2014 & 52 & HRT & Positive uptake (NE) & $\mathrm{NE}$ & + & $\mathrm{NE}$ & (31) \\
\hline Ma and Cao, 2015 & 45 & HRT & No uptake (NE) & $<1 \%$ & + & + & (32) \\
\hline Wei et al, 2015 & 47 & HRT & No uptake (NE) & $<5 \%$ & $\mathrm{NE}$ & $\mathrm{NE}$ & (3) \\
\hline Wang et al, 2016 & 48 & $\mathrm{NE}$ & Low uptake $(0.5-2.1)$ & $\mathrm{NE}$ & $\mathrm{NE}$ & $\mathrm{NE}$ & (33) \\
\hline Present case-1 & 38 & HRT & No uptake $(<1.6)$ & $<1 \%$ & $\mathrm{NE}$ & $\mathrm{NE}$ & \\
\hline Present case- 2 & 62 & Post & High uptake (20.1) & $<1 \%$ & - & - & \\
\hline
\end{tabular}

ER, estrogen receptor; PgR, progesterone receptor; HRT, hysterectomy; Pre, premenopausal; Post, postmenopausal; NE, not evaluated; $c a$, circa; 18-FDG-PET/CT, 2-deoxy-2-(fluorine-18)-fluoro-D-glucose positron emission tomography/computed tomography; $\mathrm{SUV}_{\max }$, maximum standard uptake value.

and 18-FDG-PET/CT findings was conducted. In total, 34 cases were identified in 29 reports (3,6-33). In addition to these 34 cases, the present two cases were added and a total of 36 cases of PBML were reviewed. The results are summarized in Table I. The median age of the patients included was 47 years (range, 34-69 years). A total of 5 patients were pre-menopausal,
2 were post-menopausal and 19 patients had previously received a hysterectomy. The conditions of the reproductive systems of the remaining 10 patients were unconfirmed. All of the total 36 cases were of benign leiomyoma. However, only one patient exhibited malignant transformation (16). With regard to the 18-FDG-PET/CT findings, the accumulation of 
18-FDG varied significantly. According to the discretion of the researchers, the patients were assigned into the following three groups: No (minimal) uptake, low (moderate) uptake and high (positive) uptake. A total of 25 patients $(69.4 \%)$ were assigned to the no uptake group, 8 patients $(22.2 \%)$ were assigned to the low uptake group and 3 patients $(8.3 \%)$ were assigned to the high uptake group. However, only one patient out of those 3 had a tumor that demonstrated aggressive behavior. The SUV $_{\max }$ values were identified in 13/36 cases and the median value was determined to be 2.2 (range, 1.4-20.1). The Ki-67 proliferation index ranged from $0-5 \%$ in those 13 cases and a total of $7 / 13$ cases had a Ki-67 index $<1 \%$. Consequently, there was no significant correlation observed between the uptake of 18-FDG in the tumors and the Ki-67 index. The expression of ER and PgR within the tumors was also assessed. In total, 21/23 patient tissue samples exhibited positive staining for ER (91.3\%) and 20/21 had positive staining for PgR (95.2\%). However, the patient in case 2 was determined to be double negative for ER and PgR.

It has previously been reported that $18-F D G-P E T / C T$ is useful for distinguishing malignant leiomyosarcoma from benign leiomyoma $(34,35)$. In general, SUV values for leiomyosarcoma were observed to be significantly greater than those for leiomyoma. However, numerous reports for $18-F D G-a v i d$ leiomyoma were also identified (36-38). Furthermore, a series of comprehensive analyses for those patients who underwent 18-FDG-PET/CT revealed that small proportion of benign uterine leiomyomas exhibited positive 18-FDG uptake. In the present study, a case of 18-FDG-avid PBML is detailed. Summarizing previous studies indicated that $33 \mathrm{PBML}$ cases involved 18-FDG non-avid tumors, and only 3 were 18-FDG-avid tumors. No particular phenotype was identified to be associated with 18-FDG-avid PBML. Further investigations are required in order to improve present understanding of the biological characteristics of PBML, thus leading to its optimal management.

\section{References}

1. Steiner PE: Metastasizing fibroleiomyoma of the uterus: Report of a case and review of the literature. Am J Pathol 15: 89-110.7, 1939.

2. Ki EY, Hwang SJ, Lee KH, Park JS and Hur SY: Benign metastasizing leiomyoma of the lung. World J Surg Oncol 11: 279 , 2013.

3. Wei WT and Chen PC: Benign metastasizing leiomyoma of the lung: A case report and literature review. Oncol Lett 10: 307-312, 2015.

4. Mahmoud MS, Desai K and Nezhat FR: Leiomyomas beyond the uterus; benign metastasizing leiomyomatosis with paraaortic metastasizing endometriosis and intravenous leiomyomatosis: A case series and review of the literature. Arch Gynecol Obstet 291: 223-230, 2015

5. Wada N, Nakayama H, Suganuma N, Masudo Y, Rino Y, Masuda $M$ and Imada T: Prognostic value of the sixth edition AJCC/UICC TNM classification for differentiated thyroid carcinoma with extrathyroid extension. J Clin Endocrinol Metab 92: 215-218, 2007.

6. Chan JW, Law WL, Cheung SO, Lee MP, Ng CK, Lee S, Ko KM, Ma CC, Liu JY, Chan TM and Mok TY: Benign metastasising leiomyoma: A rare but possible cause of bilateral pulmonary nodules in Chinese patients. Hong Kong Med J 11: 303-306, 2005.

7. Moon H, Park SJ, Lee HB, Kim SR, Choe YH, Chung MJ, Jin GY and Lee YC: Pulmonary benign metastasizing leiomyoma in a postmenopausal woman. Am J Med Sci 338: 72-74, 2009.
8. di Scioscio V, Feraco P, Miglio L, Toni F, Malvi D, Pacilli AM, Fasano L, Fabbri M and Zompatori M: Benign metastasizing leiomyoma of the lung: PET findings. J Thorac Imaging 24: 41-44, 2009.

9. Lee SM: Incidental multiple pulmonary nodules: Benign metastasizing leiomyoma and ${ }^{18} \mathrm{~F}-\mathrm{FDG}$ PET/CT. Nucl Med Mol Imaging 41: 258-259, 2007.

10. Londero AP, Perego P, Mangioni C, Lellé RJ, Londero F and Marchesoni D: Locally relapsed and metastatic uterine leiomyoma: A case report. J Med Case Rep 2: 308, 2008.

11. Kasai Y, Masuya D, Matsuoka H, Yoshimatsu H and Suzuki Y: Value of FDG-PET in a case of benign metastasizing leiomyoma. The J Jpn Assoc Chest Surg 23: 871-874, 2009.

12. Lin X, Fan W, Lang P, Hu Y, Zhang X and Sun X: Benign metastasizing leiomyoma identified using 18F-FDG PET/CT. Int J Gynaecol Obstet 110: 154-156, 2010.

13. Clément-Duchêne C, Vignaud JM, Régent D and Martinet Y: Benign metastasizing leiomyoma with lung cystic lesions and pneumothoraces: A case report. Resp Med CME 3: 183-185, 2010.

14. Lin TK and Bradshaw DA: Benign metastasizing leiomyoma in a patient without gynecologic symptoms. Chest 138: 89A, 2010.

15. Caminati A, Cavazza A, Mirenda MR and Harari S: A 69-year-old female with multiple, bilateral pulmonary nodules. Eur Respir Rev 20: 56-59, 2011.

16. Ogawa M, Hara M, Ozawa Y, Moriyama S, Yano M, Shimizu S and Shibamoto Y: Benign metastasizing leiomyoma of the lung with malignant transformation mimicking mediastinal tumor. Clin Imaging 35: 401-404, 2011.

17. Yoon G, Kim TJ, Sung CO, Choi CH, Lee JW, Lee JH, Bae DS and Kim BG: Benign metastasizing leiomyoma with multiple lymph node metastasis: A case report. Cancer Res Treat 43: 131-133, 2011.

18. Ni Y, Shi G, Wan H, Shen J, Jiang X and Yuan F: Pulmonary benign metastasizing leiomyoma: Case report and review of the literature. Clin Exp Obstet Gynecol 39: 249-251, 2012.

19. Nakajo M, Nakayama H, Sato M, Fukukura Y, Nakajo M, Kajiya Y, Yanagi M, Tabata K and Higashi M: FDG-PET/CT finding of benign metastasizing leiomyoma of the lung. Acta Radiol Short Rep 1: pii: arsr.2012.120012, 2012.

20. Fu Y, Li H, Tian B and Hu B: Pulmonary benign metastasizing leiomyoma: A case report and review of the literature. World J Surg Oncol 10: 268, 2012.

21. Alraiyes AH, Kheir F, Hirsh S, Salerno D, Bernal-Green L and Daroca P: A 40-year-old woman with multiple lung nodules. Chest 143: 1826-1829, 2013.

22. Okabe R, Shoji T and Huang CL: Benign metastasizing leiomyoma of the lung with spontaneous pneumothorax. Thorac Cardiovasc Surg Rep 2: 26-28, 2013.

23. Tsunooka N, Hirayama K and Inazawa K: Benign lung metastasizing leiomyoma: A report of 2 cases. Nihon Rinsho Geka Gakkai Zasshi (Journal of Japan Surgical Association) 74: 2428-2433, 2013.

24. Mogi A, Hirato J, Kosaka T, Yamaki E and Kuwano H: Benign metastasizing leiomyoma of the lung: Report of a case. Gen Thorac Cardiovasc Surg 61: 719-722, 2013.

25. Chen S, Zhang Y, Zhang J, Hu H, Cheng Y, Zhou J, Shen L and Chen H: Pulmonary benign metastasizing leiomyoma from uterine leiomyoma. World J Surg Oncol 11: 163, 2013.

26. Ağaçkiran Y, Findik G, Ustün LN, Aydoğdu K and Kaya S: Pulmonary benign metastasizing leiomyoma: An extremely rare case. Turk Patoloji Derg: Apr 9, 2014 (Epub ahead of print).

27. Loukeri AA, Pantazopoulos IN, Tringidou R, Giampoudakis P, Valaskatzi A, Loukeri PA and Kampolis CF: Benign metastasizing leiomyoma presenting as cavitating lung nodules. Respir Care 59: e94-e97, 2014.

28. Jeon HW, Choi SH, Sung SW and Park JK: Pulmonary benign metastasizing leiomyoma: Report of three cases. World J Surg Oncol 11: 281, 2013.

29. Okita R, Yasuda K, Nojima Y, Maeda A, Yukawa T, Saisho S, Shimizu K, Akiyama T, Miyagi Y, Oda T and Nakata M: CT, MRI and ${ }^{18}$ F-FDG PET-CT findings of pulmonary benign metastasizing leiomyoma: A case report. Open J Thoracic Surg 3: 127-129, 2013.

30. Jin X, Meng Y, Zhu Z, Jing H and Li F: Elevated 99mTc 3PRGD2 activity in benign metastasizing leiomyoma. Clin Nucl Med 38: 117-119, 2013.

31. Taftaf R, Starnes S, Wang J, Shipley R, Namad T, Khaled R and Abdel Karim N: Benign metastasizing leiomyoma: A rare type of lung metastases-two case reports and review of the literature. Case Rep Oncol Med 2014: 842801, 2014. 
32. $\mathrm{Ma} \mathrm{H}$ and $\mathrm{Cao} \mathrm{J}$ : Benign pulmonary metastasizing leiomyoma of the uterus: A case report. Oncol Lett 9: 1347-1350, 2015.

33. Wang HC, Wang YB, Chen XH and Cui LL: Uterine intravenous leiomyomatosis with intracardiac extension and pulmonary benign metastases on FDG PET/CT: A case report. Korean J Radiol 17: 289-294, 2016.

34. Schwarzbach MH, Dimitrakopoulou-Strauss A, Willeke F, Hinz U, Strauss LG, Zhang YM, Mechtersheimer G, Attigah N, Lehnert T and Herfarth C: Clinical value of [18-F] fluorodeoxyglucose positron emission tomography imaging in soft tissue sarcomas. Ann Surg 231: 380-386, 2000.

35. Nagamatsu A, Umesaki N, Li L and Tanaka T: Use of 18F-fluorodeoxyglucose positron emission tomography for diagnosis of uterine sarcomas. Oncol Rep 23: 1069-1076, 2010 .
36. Ak I, Ozalp S, Yalcin OT, Zor E and Vardareli E: Uptake of 2-[18F]fluoro-2-deoxy-D-glucose in uterine leiomyoma: Imaging of four patients by coincidence positron emission tomography. Nucl Med Commun 25: 941-945, 2004.

37. Shida M, Murakami M, Tsukada H, Ishiguro Y, Kikuchi K, Yamashita E, Kajiwara H, Yasuda M and Ide M: F-18 fluorodeoxyglucose uptake in leiomyomatous uterus. Int J Gynecol Cancer 17: 285-290, 2007.

38. Vriens D, de Geus-Oei LF, Flucke UE, van der Kogel AJ, Oyen WJ, Vierhout ME and van der Meer JW: Benign uterine uptake of FDG: A case report and review of literature. Neth J Med 68: 379-380, 2010. 